\title{
A Comparison between cutting and folding modes of an extruded aluminum alloy tube during impact using ductile failure criterion
}

\author{
Javad Marzbanrad ${ }^{1}$, Behrooz Mashadi ${ }^{1}$, Amir Afkar $^{1,2, a}$ and Sadegh Mahdavi ${ }^{1}$ \\ 1 School of Automotive Engineering, Iran University of Science and Technology, Tehran, Iran \\ 2 Faculty of Electrical, Mechanical and Construction Engineering, Department of Automotive Engineering, \\ Standard Research Institute (SRI), Karaj P.O. Box 31745-139, Iran
}

Received 13 January 2015, Accepted 9 July 2015

\begin{abstract}
Thin-walled structures like crash boxes may be used as energy absorbers in the automotive chassis. There have been lots of investigations about the behavior of these parts during frontal crashes. Previous researches show that thin-walled circular tube has the highest energy absorption among different structures. In this study, cutting and folding modes of extruded aluminum tubes (EN-7018 T6) with $50 \mathrm{~mm}$ diameter, lengths of 300 and $400 \mathrm{~mm}$ and thicknesses of 2, 2.5 and $3 \mathrm{~mm}$ are compared when axial impacts with velocities of 6,8 and $10 \mathrm{~m} . \mathrm{s}^{-1}$ are applied to them. Cutting tools of 4 and 6 blades are used to provide the cutting mode. Effective parameters of energy absorbers including crush force efficiency, specific energy absorption and maximum axial load are modeled numerically with the help of Hooputra's ductile damage criterion and are compared to each other for three cases of aluminum tube folding between two rigid plates and tube rupture by using 4 and 6 blades cutting tools. The analyses show that the tube rupture by the 6 blades cutting tool is better than the other two in the case of energy absorption. Furthermore, the results demonstrate that tube cutting with the help of multi-blades cutting tools is more stable, controllable and predictable than tube folding.
\end{abstract}

Key words: Thin-walled structure / cutting deformation / energy absorption / ductile failure criterion

\section{Introduction}

Thin-walled beams are widely used as crash absorbers in the automotive chassis. Such kinds of structures are frequently used in the vehicle front parts. These parts play an important role in energy absorption during frontal crashes. Thin-walled tubes absorb kinetic energy of the crash via plastic deformation to protect vehicle occupants. These elements are specifically designed to absorb high amounts of energy during a crash to ensure passenger cabin integrity and hence the passenger safety.

The use of lightweight materials has increased recently to reduce the weight of vehicle body and the fuel consumption [1]. Multiple alternatives such as advanced highstrength steels, aluminum or magnesium alloys, and composite materials have been proposed to replace mild steel applications in the automotive structure [2].

Due to its low weight and being a corrosion resistor, aluminum alloy is a good alternative that can be recycled with much less required energy than that needed to produce primary aluminum. The prospect shows that for

\footnotetext{
${ }^{a}$ Corresponding author: afkar@iust.ac.ir
}

example, in Europe, the aluminum consumption will face the increase of 30\% until 2020 as shown in Figure 1 [3].

The energy absorption and the maximum impact load of an aluminum crash box during a crash depend on many parameters such as geometry, strain-rate sensitivity, plastic deformation history of metalwork, porosity of materials, temperature during crash, boundary conditions and impact energy (mass and velocity of the striker).

Splitting circular metal tubes are an efficient energy absorption method to dissipate undesirable energies in many structures such as automotive ones. Use of splitting process has many advantages in comparison to other energy absorber systems since there are various failure mechanisms in the whole process such as bending, stretching and tearing.

Alavi and Haddad [4] investigated deformations and energy absorption capacity of thin-walled tubes with various section shapes (circular, square, rectangular, hexagonal, triangular, pyramidal and conical) both experimentally and numerically. The tubes have the same volume, height, average section area, thickness and material and are subjected under axial quasi static loading. The results of simulations are in good agreement with 


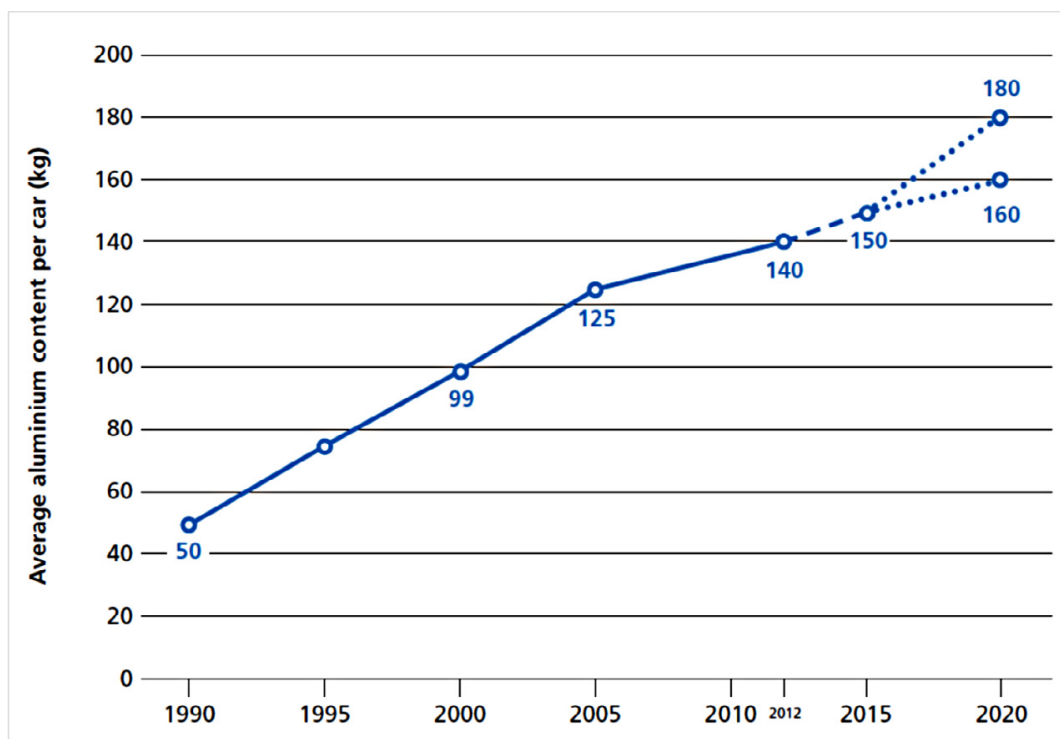

Fig. 1. Evolution of the average aluminum content per car produced in Europe [3].

the experimental data and show that the section geometry has considerable effect on the energy absorption. The circular tube has the most energy absorption capacity and the most average force among all investigated sections.

Reid [5] studied different deformation modes such as splitting, inversion and folding in circular tubes subjected to axial loadings. It was shown that plastic deformation is a major mechanism for dissipating kinetic energy. The mechanisms which involve fracture such as splitting process can use plastic deformation as a good energy absorber.

Zhou and Wang [6] studied the coalescence splitting mechanism of crack-weakened brittle materials subjected to compressive load by using the improved near crack line analysis method and simplification of crack development mechanism. They presented some analytical relations to estimate stress components near the crack line.

Cheng and Altenhof [7] developed and used a cutting device in Quasi-static axial compressive tests of square cross section AA6061-T6 extrusions to generate a cutting deformation mode of the extrusions. For the extrusions which experienced the cutting deformation mode two energy dissipating mechanisms were observed, namely, a cutting deformation mechanism and petalled sidewall outward bending mechanism. The bending energy absorption mechanism accounted for approximately $25 \%$ of the total energy absorption.

Jin et al. [8] studied the load/displacement and energy-absorption characteristics of AA6061-T6 round extrusions under a cutting deformation mode via experimental testing. Tube length appeared to have no significant influence on the load/displacement response of the extrusions, which experienced the cutting mode of deformation. The average crush force efficiency for extrusions, which experienced the cutting mode of deformation, was approximately 0.95 independent of tube length. The average $\mathrm{CFE}$ of specimens which experienced progressive folding and global bending deformation modes were 0.66 and 0.20 , respectively.

Majumder et al. [9] investigated experimentally a cutting deformation mode of AA6061 T4 and T6 round extrusions with two different wall thicknesses of 1.587 and $3.175 \mathrm{~mm}$ under quasi-static loading conditions. Clean cutting behavior was observed for the extrusions with a T6 temper and wall thickness of $1.587 \mathrm{~mm}$ and for extrusions with a T4 temper and wall thickness of $3.175 \mathrm{~mm}$.

Jin and Altenhof [10] proposed an analytical deformation model for axial cutting of circular tubes by using a cutter with multiple blunt blades and compared their model with experimental measurements. The effect of the friction force was included in the proposed solution and the steady-state axial cutting force was determined through the use of the principle of virtual power.

Yuen et al. [11] demonstrated the experimental data on the axial splitting of circular aluminum extrusions under a blast loading condition using a cutting tool and deflector configurations were performed with a good degree of repeatability and controllability. The thick-walled extrusions exhibit better repeatability and controllability during the tests. The increase in wall thickness provided more contact surface area between the extrusions and the blade hence making them less susceptible to misalignment. In general, the length of cut depth was observed to increase with the increase of charge mass used and decreased with the increase in wall thickness.

Niknejad et al. [12] derived some theoretical relations to predict the axial force during the splitting process on circular metal tubes. They introduced a new theoretical model of deformation that divides the splitting process into five different stages. This study showed that when the semi-angle of die increases, the maximum splitting force and the steady force increase. By increasing the number of initial slits, tube diameter and tube wall thickness, the splitting force increases, too. Also, the axial load of the 
splitting process is enhanced when the initial slits length decreases.

Marzbanrad et al. [13] considered the stress-strain sensitivity effect on box behavior during a crash by creating elastic and plastic boundary conditions instead of rigid boundary conditions on the bottom of a crash box. In addition, the effect of elastic and plastic boundary conditions on the energy absorption of circular tubes under impact force is numerically investigated. The ductile failure criterion is employed to accurately obtain crashworthiness simulation results. Results reveal that the use of elastic boundary can change deformation mode and decrease the maximum impact force.

Generally, there are two methods to develop rupture process in tubes:

- Use of cone-shaped rigid rod.

- Use of cutting tools.

Although the energy absorption is sufficient when the rupture occurs by the conical rod, this kind of process has its own disadvantages:

- Crush force efficiency reduction due to high maximum force at the beginning of process.

- Unpredictable petal numbers and rupture path.

- Variable amount of energy absorption and nonrepeatability of the process.

- Numerous problems with using this method as an energy absorption system in vehicles during collision, because of heavy weight and high required space above the conical rod which must be embedded inside the vehicle.

- In the previous studies the load is applied quasi statically to the tube. The dynamic mode has not been investigated.

Rupture with the help of cutting tools is studied in two ways. One is the case when the load is applied to the cutting tool and the tool moves while the tube is stationary; the other one is when the cutting tool is fixed and the impact strikes the tube (the tube is moving). The second case is less applicable in comparison to the first one because of packaging problems and cutting tool fixing. Most researches have studied the rupture statically with the help of cutting tool while the cutting process dynamics has not been investigated. Moreover, the studies have been done experimentally and the cutting process has not been modeled. Besides, no comparison has been done between folding and cutting modes of tubes in order to identify the differences between the two modes. In this study, three cases are modeled numerically: tube folding between two rigid flat plates and tube rupture with the help of 4 blades and 6 blades cutting tools when the impact is applied axially to the aluminum tube. The results of this modeling are obtained and compared for different impact velocities and various geometries of the aluminum tube.

\section{Modeling}

\subsection{Hooputra's ductile damage (HDD) criterion}

In 2004 a group of researchers in Germany's BMW automobile company, directed by Hooputra, proposed a comprehensive approach for predicting a component failure based on macroscopic strains and stresses [14]. This approach requires the use of a number of different failure mechanism representations, such as necking (due to local instabilities), as well as ductile and shear fracture. All the failure criteria have been developed in a way to include the effect of nonlinear strain paths. They experimentally obtained the material parameters of aluminum alloy EN AW-7108 T6 for quasi-static and dynamic cases, and using these criteria could accurately predict the failure of aluminum parts. The Hooputra's ductile fracture criterion is based on Kolmogorov's mathematical model [15], and represents the equivalent strain as a function of the stress triaxiality. Regarding the non-uniform effect of increasing the equivalent strain affected by the stress triaxiality growth, three dependent parameters are considered for the isotropic materials. For these materials, the criterion is defined as:

$$
\begin{aligned}
D & =\int_{0}^{\bar{\varepsilon}_{f}} \frac{\mathrm{d} \bar{\varepsilon}}{\bar{\varepsilon}_{f}(\eta)} \\
\bar{\varepsilon}_{f}(\eta) & =a e^{-c \eta}+b e^{c \eta} \\
\eta & =\frac{\sigma_{m}}{\bar{\sigma}}
\end{aligned}
$$

where $\bar{\varepsilon}_{f}, \sigma_{m}, \bar{\sigma}$ and $\eta$ are the fracture equivalent strain, mean stress, Von Mises equivalent stress and the stress triaxiality, respectively. Furthermore, $D$ indicates damage variable, which changes from raw material to ruptured material. Symbols $a, b$, and $c$ are the material parameters which are experimentally extracted from waisted tensile specimen [16], Erichsen's cupped test, and three-point bending test of double chamber extrusion component. In the above-mentioned tests, the values of stress triaxiality are $1 / 3,2 / 3$ and $1 / \sqrt{3}^{10}$, respectively.

\subsection{Numerical analysis}

ABAQUS/Explicit software is used to perform the numerical simulations. Four-node shell elements with reduced integration (ABAQUS S4R) are employed to describe the circular tube tests with aluminum alloy EN AW-7108 T6. The isotropic hardening properties (true stress vs. plastic strain) of this material are shown in Figure 2 [14].

This model was previously used for impact of aluminum alloy EN AW-7108 T6 tube with a circular cross section and for aluminum alloy 6063-T4 tube with a square cross section during folding and was verified with the help of experimental results $[13,17]$. A sample of model results in comparison to experimental results is shown in Figure 3. 


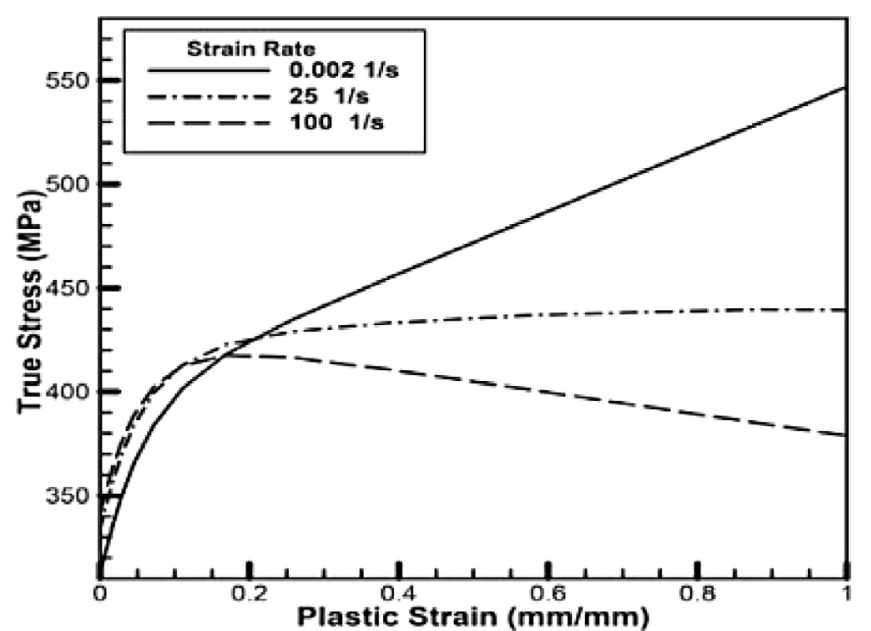

Fig. 2. Stress-strain curve at different strain rates [14].

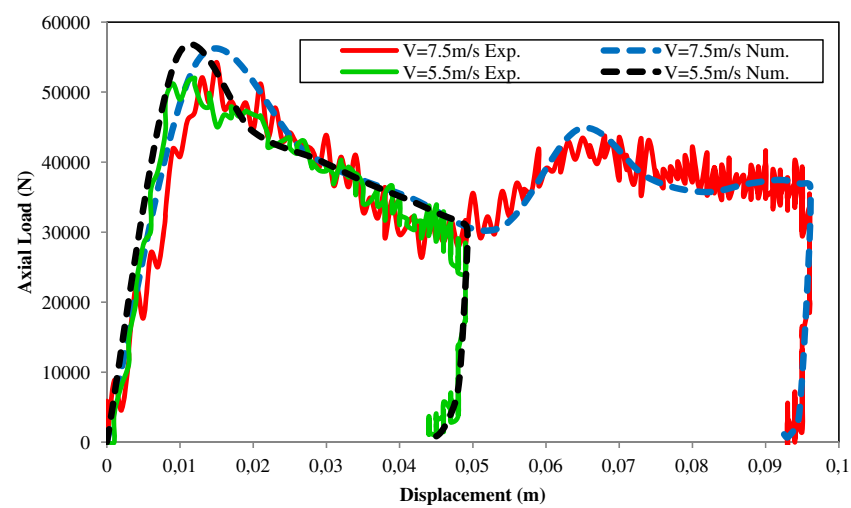

Fig. 3. Comparison diagrams of model and experimental results of force versus displacement for tube axial impact with two velocities of 7.5 and $5.5 \mathrm{~m} . \mathrm{s}^{-1}$ during folding [17].

Moreover, this model is used for quasi-statically tube cutting simulation with cutting tools based on experimental study of Majumder [9]. To make this model of cutting tools, similar dimensions of four-blade (model A) tools of Majumder are used. Tube length is $300 \mathrm{~mm}$, its external diameter is $50.8 \mathrm{~mm}$, its thickness is $3.175 \mathrm{~mm}$ and is made up of aluminum alloy AA6061-T4. Comparison diagram of axial force versus displacement during quasistatically cutting by the cutting tool is shown in Figure 4. As it is seen, the model results have proper accuracy in comparison to the experimental study.

In this study, three kinds of strikers are used to strike the aluminum alloy tube. These three include: a rigid flat plate for tube folding and two kinds of solid cutting tools with 4 and 6 blades to provide cutting mode in the tube. The cutting tools with 4 and 6 blades are shown in Figure 5. The thicknesses of cutting edges are chosen in a way that their sum in 4 and 6 blades are equal to each other, namely:

$$
t_{\text {Total }}=2.5 \times 4(\text { blade })=1.66 \times 6(\text { blade })
$$

The depth of both cutting tools is the same and equal to $30 \mathrm{~cm}$.

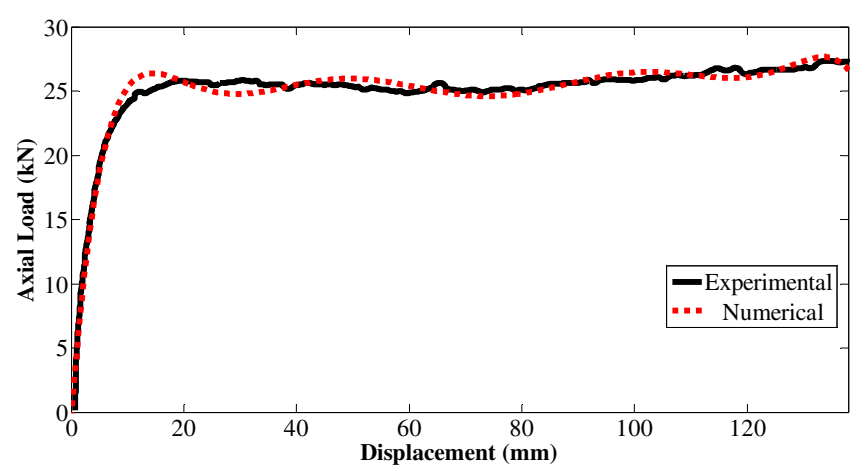

Fig. 4. Comparison diagram of model and experimental results [9] of force versus displacement for quasi-statically tube cutting with the help of cutting tools.
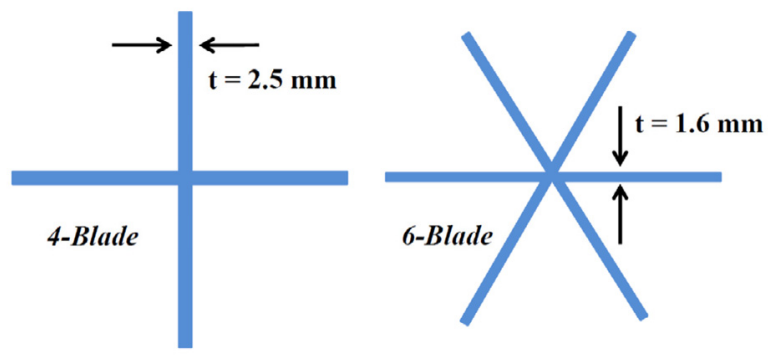

Fig. 5. Front view of cutting tools with 4 and 6 blades.

All the strikers are regarded as a point mass of $100 \mathrm{~kg}$ with different initial velocities of $V=6,8$ and $10 \mathrm{~m} . \mathrm{s}^{-1}$ in one direction. Due to the striker's rigidity assumption and also restraining it in all directions except the axial one (a longitudinal direction), the mass is considered as lumped for simplicity in modeling. The contact between tube and striker is defined as the surface-to-surface interaction with a friction coefficient of 0.2 . Besides, double surface self-contact is defined considering the whole tube surface with a friction coefficient of 0.15 [14]. The material is strain-rate-sensitive aluminum alloy (EN AW-7108 T6) with Young modulus and mass density of $E=70 \mathrm{GPa}$ and $\rho=2700 \mathrm{~kg} \cdot \mathrm{m}^{-3}$, respectively. The tube dimensions include: diameter $D=50 \mathrm{~mm}$, lengths $L=300$ and $400 \mathrm{~mm}$ and wall thicknesses $t=2.0,2.5$ and $3.0 \mathrm{~mm}$.

Frequency parameters are used to estimate the energy absorption capability of thin-walled tubes. Some of the most important parameters which are obtained in this study are:

- Total energy absorption

$E_{\text {Absorbed }}$ is defined as the tube external work which can be calculated as:

$$
E_{\text {Absorbed }}=T E A=\int P(\delta) d \delta=\sum_{i=2}^{N-1} P_{i}\left(\frac{\delta_{i+1}-\delta_{i-1}}{2}\right)
$$

where $P(\delta)$ is a function of crash load based on the tube displacement $(\delta)$.

In fact, the area under the force-displacement diagram must be calculated to obtain total energy absorption. 

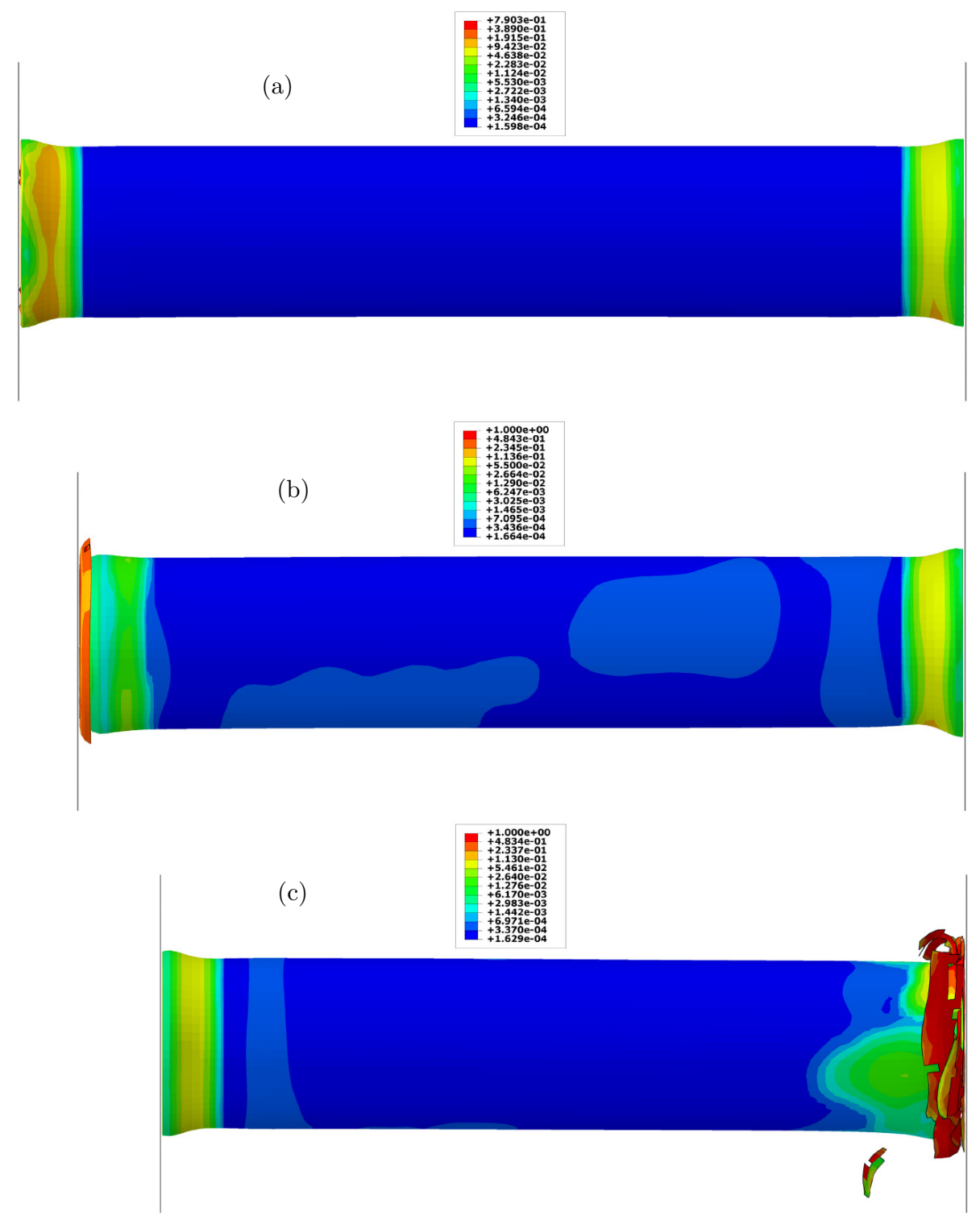

Fig. 6. Distributions of damage variable $(D)$ for tube folding between two flat plates with length of $300 \mathrm{~mm}$ and thickness of $2.5 \mathrm{~mm}$ in different velocities: (a) $V=6 \mathrm{~m} \cdot \mathrm{s}^{-1}$, (b) $V=8 \mathrm{~m} \cdot \mathrm{s}^{-1}$, (c) $V=10 \mathrm{~m} \cdot \mathrm{s}^{-1}$.

- Peak crush force

Peak crush force is demonstrated by $P_{\text {Max }}$ and is the maximum force which is applied axially to the part.

- Mean crush force

$$
P_{m}=\frac{\sum_{i=2}^{N-1} P_{i}\left(\frac{\delta_{i+1}-\delta_{i-1}}{2}\right)}{\delta_{t}}
$$

which is obtained via division of total energy absorption to total crush displacement $\left(\delta_{t}\right)$.

- Crush force efficiency (CFE)

$$
C F E=\frac{P_{m}}{P_{\operatorname{Max}}}
$$

- Specific energy absorption (SEA)

$$
S E A=\frac{E_{\text {Absorbed }}}{m}
$$

where $m$ is the tube mass which absorbs energy during impact.

\section{Results and discussion}

Figures 6 to 8 display distributions on Hooputra's ductile damage variable $(D)$ from raw to ruptured material.

Figure 6 belongs to the case that the alloy aluminum tube, which is placed between two rigid plates (one is fixed and the other moves in one direction), is struck with velocities of 6,8 and $10 \mathrm{~m} . \mathrm{s}^{-1}$. It shows the moment when the maximum displacement of striker occurs. This figure relates to the tube with the length of $300 \mathrm{~mm}$ and the thickness of $2.5 \mathrm{~mm}$. It is clear that the damage 

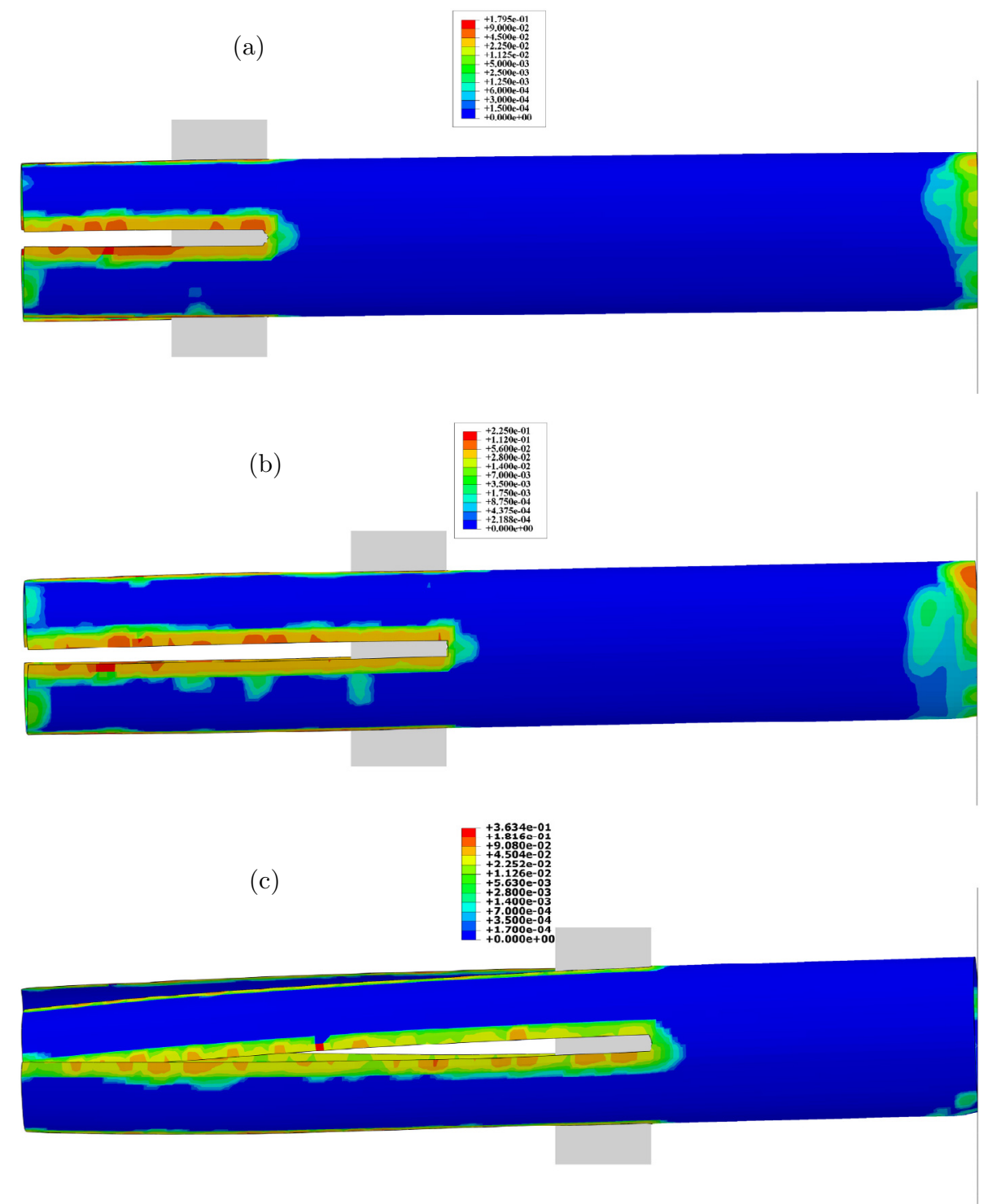

Fig. 7. Distributions of damage variable $(D)$ for tube rupture with length of $300 \mathrm{~mm}$ and thickness of $2.5 \mathrm{~mm}$ in different velocities by the 4 blades cutting tool: (a) $V=6 \mathrm{~m} \cdot \mathrm{s}^{-1}$, (b) $V=8 \mathrm{~m} \cdot \mathrm{s}^{-1}$, (c) $V=10 \mathrm{~m} \cdot \mathrm{s}^{-1}$.

is higher for high velocities and usually happens at tube ends. Tube damage during folding at either ends depends on different factors including tube length, tube diameter, tube thickness, tube material, velocity and mass of the striker, support type and etc. hence its prediction is so difficult [13].

Figure 7 relates to the case that the aluminum alloy tube is supported to the rigid flat plate from one side and from the other side, it is struck axially by the 4 blades rigid cutting tool (according to Fig. 5) with velocities of 6,8 and $10 \mathrm{~m} \cdot \mathrm{s}^{-1}$. Tube dimensions are as the previous case. As it is evident, the cutting tool feed inside the tube increases with the increase of velocity. Also, the rupture happens in a path which is predictable.

Figure 8 is similar to the previous case with the exception that instead of 4 blades cutting tool, the 6 blades one (Fig. 5) is being used.
As it is known, the energy absorption of tube cutting process is done through three manners:

1. Energy absorption at the wedge area of cutting tool when the cutting wedge penetrates inside the tube sheet.

2. Energy absorption due to friction between cutting tool surfaces and the tube.

3. Energy absorption due to plastic deformation inside the tube.

The tool feed inside the tube with 4 blades cutting tool (Fig. 7) is more than the 6 blades one (Fig. 8) due to lower friction between tool and tube. The reason of lower friction is because of smaller contact surface of 4 blades tool than the 6 blades one. Besides, a significant plastic deformation is not seen in the ruptured tube in the case of 4 blades tool (Fig. 7). However, for the 6 blades tool (Fig. 8), because the blades are closer to each other 

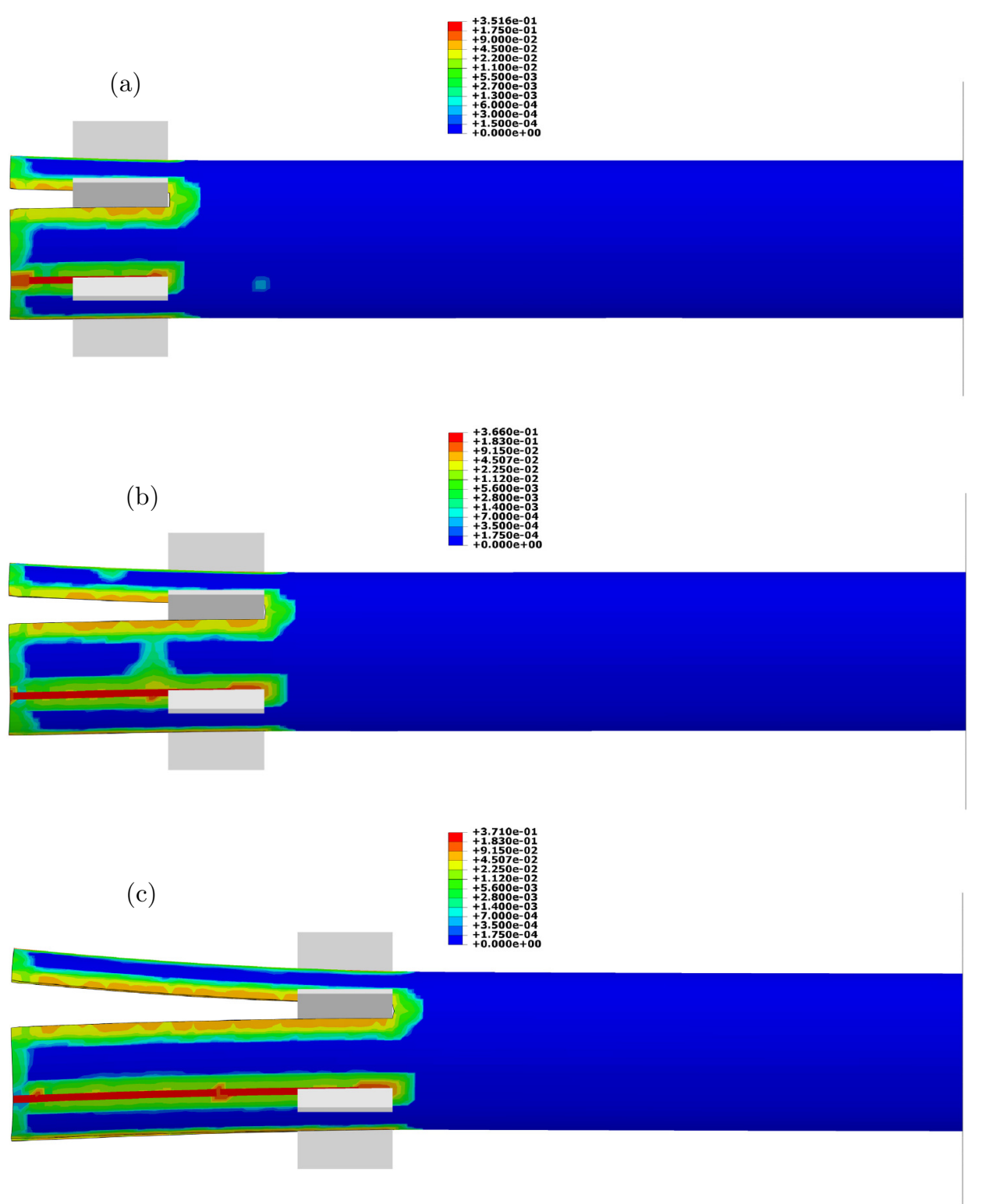

Fig. 8. Distributions of damage variable $(D)$ for tube rupture with length of $300 \mathrm{~mm}$ and thickness of $2.5 \mathrm{~mm}$ in different velocities by the 6 blades cutting tool: (a) $V=6 \mathrm{~m} \cdot \mathrm{s}^{-1}$, (b) $V=8 \mathrm{~m} \cdot \mathrm{s}^{-1}$, (c) $V=10 \mathrm{~m} \cdot \mathrm{s}^{-1}$.

in comparison to the 4 blades one, the provided sheets of tube rupture bend towards outside of the tube center which will increase the energy dissipation.

Figure 9 shows axial load in terms of displacement during tubes folding with length of $300 \mathrm{~mm}$ and thicknesses of $2,2.5$ and $3 \mathrm{~mm}$ between two flat plates with velocities of 6,8 and $10 \mathrm{~m} . \mathrm{s}^{-1}$. As it is seen, the displacement is larger for the cases with higher striker velocity and the displacement has direct relationship with velocity. Also, when the tube is thicker, the maximum load is higher and hence the displacement is smaller. The maximum load usually happens at the process beginning which is like applying a shock to the system. When an aluminum tube is used as a crash box in vehicles, this high maximum load which occurs at the impact beginning hurts the vehicle passengers. To reduce crash damages, it is required that vehicle safety systems, like seat belts and airbags, react quickly. For reactions in high velocities, more expensive technologies are needed. Tubes with equal thicknesses have almost similar behavior in different velocities. This behavior changes significantly with the change of tube thickness. As it is observed, for equal tube thicknesses, the maximum primary load is independent of velocity, approximately, and have equal maximum load for different velocities during impact.

Figure 10 shows diagrams of axial load versus displacement during tubes rupture of $300 \mathrm{~mm}$ length and thicknesses of 2, 2.5 and $3 \mathrm{~mm}$ in velocities of 6,8 and $10 \mathrm{~m} . \mathrm{s}^{-1}$ by the 4 blades cutting tool. As it is seen, like the folding case, when the striker velocity is higher, the displacement is larger; and displacement and velocity have straight relationship. Moreover, when the tube thickness is higher, 

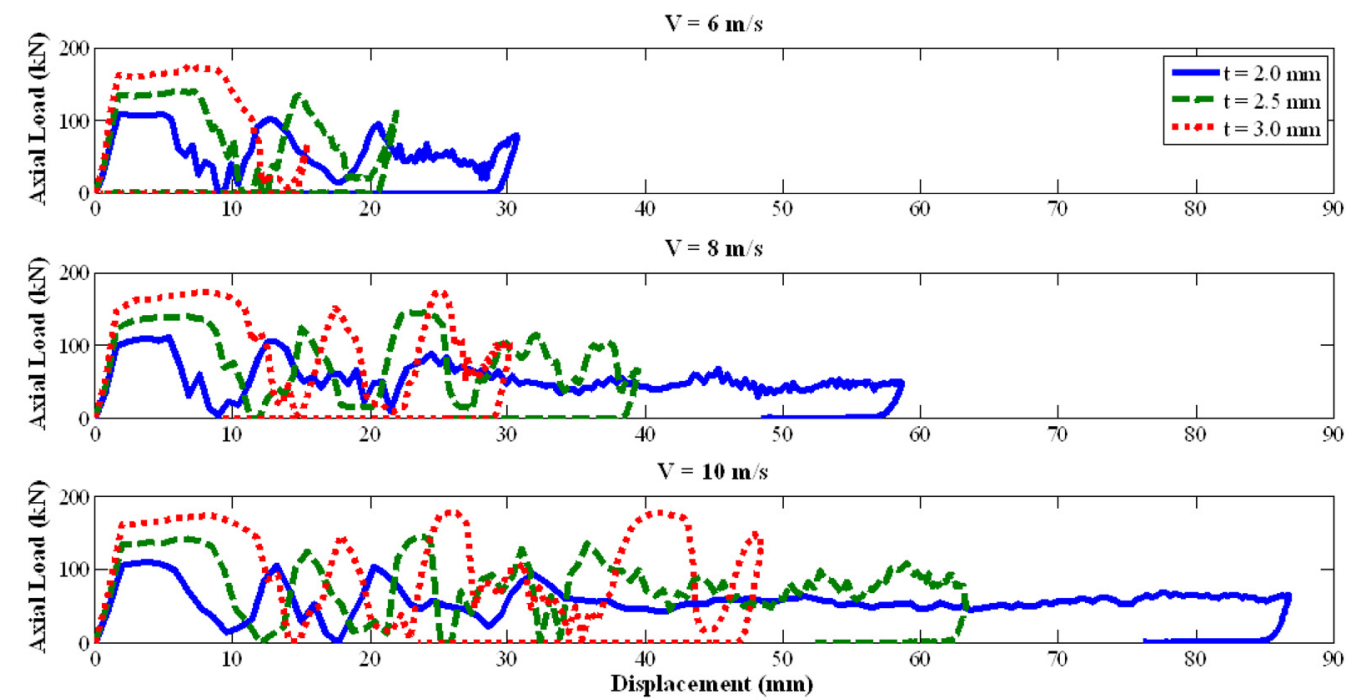

Fig. 9. Axial load in terms of displacement in a crash box of $300 \mathrm{~mm}$ length during folding under impact.
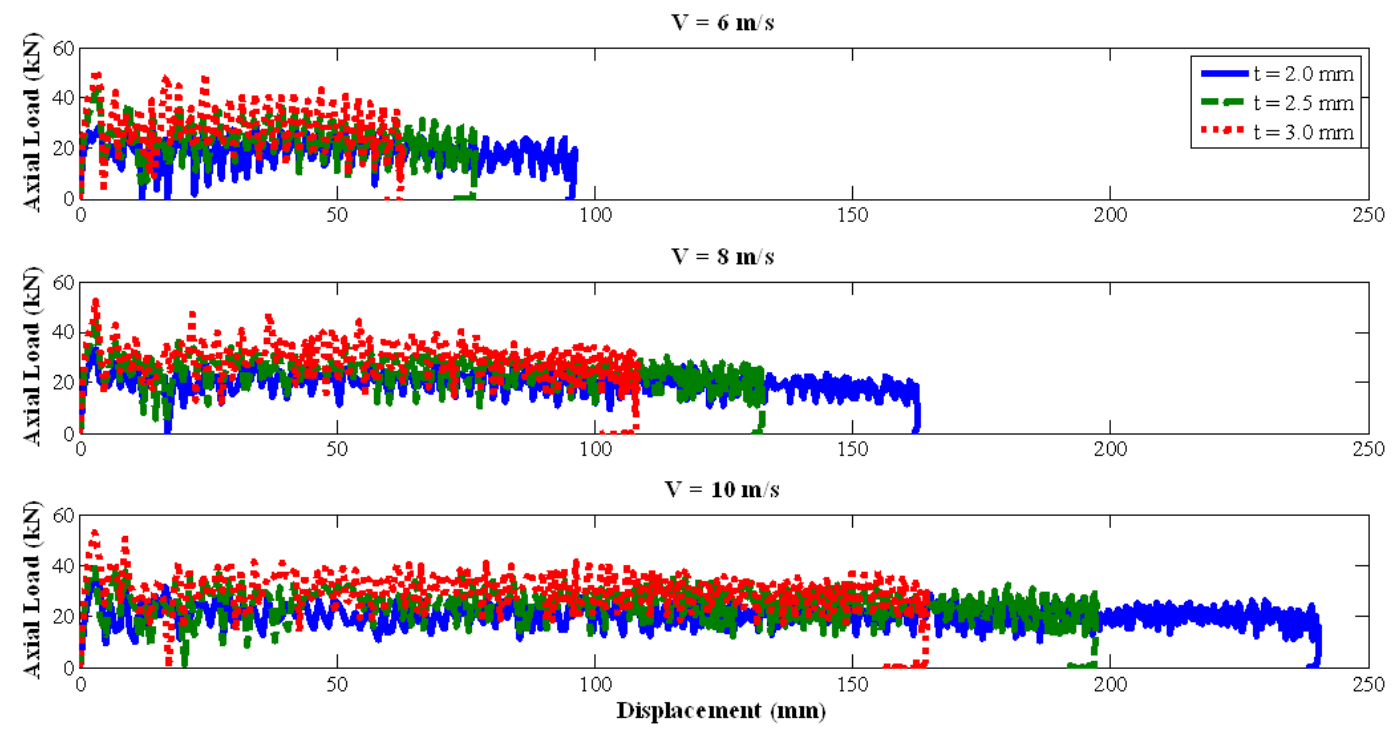

Fig. 10. Axial load in terms of displacement in a crash box of $300 \mathrm{~mm}$ length during tube rupture by the 4 blades cutting tool.

the maximum load is higher and hence the displacement is smaller; although the maximum load variations of cutting case are not the same as the folding case. In cutting process, the load is followed periodically with low range in a straight path. If the contact surface of the cutting tool and tube decreases (the tool depth reduces), the measure of load variations decreases due to the reduction of frictional energy losses. Tubes with the same thicknesses have similar behavior during cutting with different velocities. Unlike the folding case between two rigid plates, the cutting process behavior doesn't change much with tube thickness changes.

Figure 11 illustrates axial load versus displacement like the previous case with the exception that the rupture occurs by the 6 blades cutting tool. The characteristics of the case of using 4 blades tool are also established in this case; however, the lost energy via friction force is more than cutting energy loss due to the increase of contact surfaces between tube and cutting tool. This causes the maximum axial load to happen in the middle of the process rather than the process beginning.

In Figure 12, diagrams of axial load in terms of displacement are compared for the process of tube folding between two rigid flat plates and tube rupture by 4 and 6 blades cutting tools. As it is observed, high maximum load, high range and irregular variations are some specifications of folding between two rigid plates. However, for rupture by 4 and 6 blades tools, the maximum load is low, and the variations range is lower and more regular. Tube thickness is $2 \mathrm{~mm}$ for this figure.

Figure 13 shows diagrams of axial load versus displacement during comparison of tubes with 300 and $400 \mathrm{~mm}$ lengths with striker velocity of $10 \mathrm{~m} . \mathrm{s}^{-1}$ and thickness of $2 \mathrm{~mm}$ for three cases of folding between two rigid 

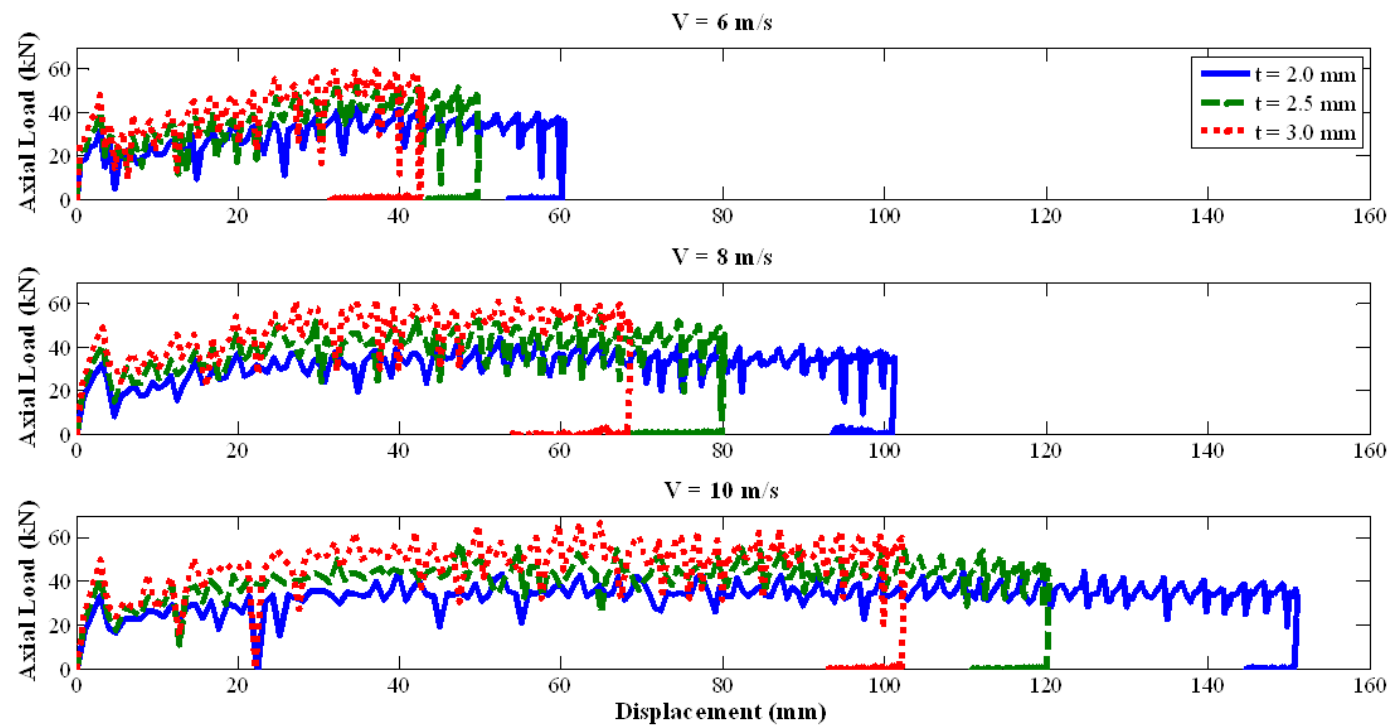

Fig. 11. Axial load in terms of displacement in a crash box of $300 \mathrm{~mm}$ length during tube rupture by the 6 balades cutting tool.

plates and tube rupture by 4 and 6 blades cutting tools. For all cases, when the tube length is $400 \mathrm{~mm}$, the feed measure inside the tube is more than the $300 \mathrm{~mm}$ tube length. There is not much difference for lengths of 300 and $400 \mathrm{~mm}$ when comparing tube behavior in three cases. However, this difference is higher for the case of folding between two plates. With the increase of tube length, the process tends to global bending from progressive folding which decreases significantly the energy absorption characteristics. Global bending occurs later for the tube cutting situation. The level of maximum and mean load of cutting case is so lower than the folding case and proportionally, the buckling probability of the tube decreases. Furthermore, tube diameter and thickness reduction and increase of impact velocity, enhance the buckling tendency in the tube.

All the obtained measures for three cases of tube folding between two plates and tube rupture by 4 and 6 blades cutting tools for tube lengths of 300 and $400 \mathrm{~mm}$ are presented in Tables 1 and 2.

Tables 1 and 2 illustrate the maximum displacement for three cases of tube folding between two plates and tube rupture by 4 and 6 blades cutting tools when the impact is applied with velocities of 6,8 and $10 \mathrm{~m} . \mathrm{s}^{-1}$ to the tubes with thicknesses of $2,2.5$ and $3 \mathrm{~mm}$ and lengths of 300 and $400 \mathrm{~mm}$. Descending maximum values of displacement relate to the rupture by the 4 and 6 blades cutting tools and folding between two plates, respectively. As it is seen, the displacement increases with the increase of impact velocity. The maximum displacement of tubes with lengths of 300 and $400 \mathrm{~mm}$ are 240.5 and $248.4 \mathrm{~mm}$, respectively when the velocity is maximum $\left(10 \mathrm{~m} . \mathrm{s}^{-1}\right)$ and the tube thickness is minimum $(2 \mathrm{~mm})$ during tube rupture by 4 blades cutting tool. The minimum displacements of the tubes with 300 and $400 \mathrm{~mm}$ lengths are 15.45 and $12.01 \mathrm{~mm}$, respectively, when the velocity is minimum $\left(6 \mathrm{~m} . \mathrm{s}^{-1}\right)$ and the thickness is maximum $(3 \mathrm{~mm})$ during folding of tube between two plates.

In Tables 1 and 2, the maximum axial loads are illustrated for the three cases. The lower the maximum axial load is the better for the tube as an energy absorber inside the vehicle during impact. The higher maximum axial load causes more severe harms to the vehicle passengers. The maximum axial load during tube folding between two plates is more than the other two rupture cases with cutting tools for all the situations. The second place belongs to rupture by the 6 blades cutting tool and the lowest maximum axial load relates to the cutting by the 4 blades tool. The maximum axial load increases with the increase of tube thickness for all cases. Also, the maximum axial load increases slightly with the increase of velocity in all cases and can be neglected. The highest maximum axial loads for tube lengths of 300 and $400 \mathrm{~mm}$ are 177.5 and $175.8 \mathrm{kN}$ when the velocity is maximum $\left(10 \mathrm{~m} . \mathrm{s}^{-1}\right)$ and the tube thickness is maximum $(3 \mathrm{~mm})$ during tube folding between two plates. The lowest maximum axial loads for tube lengths of 300 and $400 \mathrm{~mm}$ are 29.42 and $29.55 \mathrm{kN}$ when the velocity is minimum $\left(6 \mathrm{~m} . \mathrm{s}^{-1}\right)$ and the tube thickness is minimum $(2 \mathrm{~mm})$ during tube rupture by the 4 blades cutting tool.

In Tables 1 and 2, the mean axial loads are shown for the three cases. The behavior of mean axial load is similar to maximum axial load behavior which is described earlier with the exception that for the folding case between two plates, the mean axial load decreases with the increase of velocity for a same tube thickness. The highest mean axial loads for the lengths of 300 and $400 \mathrm{~mm}$ are 113.4 and $136.9 \mathrm{kN}$ when the velocity is minimum $\left(6 \mathrm{~m} . \mathrm{s}^{-1}\right)$ and the tube thickness is maximum $(3 \mathrm{~mm})$ during tube folding between two plates. The lowest mean axial load with tube lengths of 300 and $400 \mathrm{~mm}$ are 18.55 and $17.37 \mathrm{kN}$, respectively, when the velocity is minimum $\left(6 \mathrm{~m} . \mathrm{s}^{-1}\right)$ and 

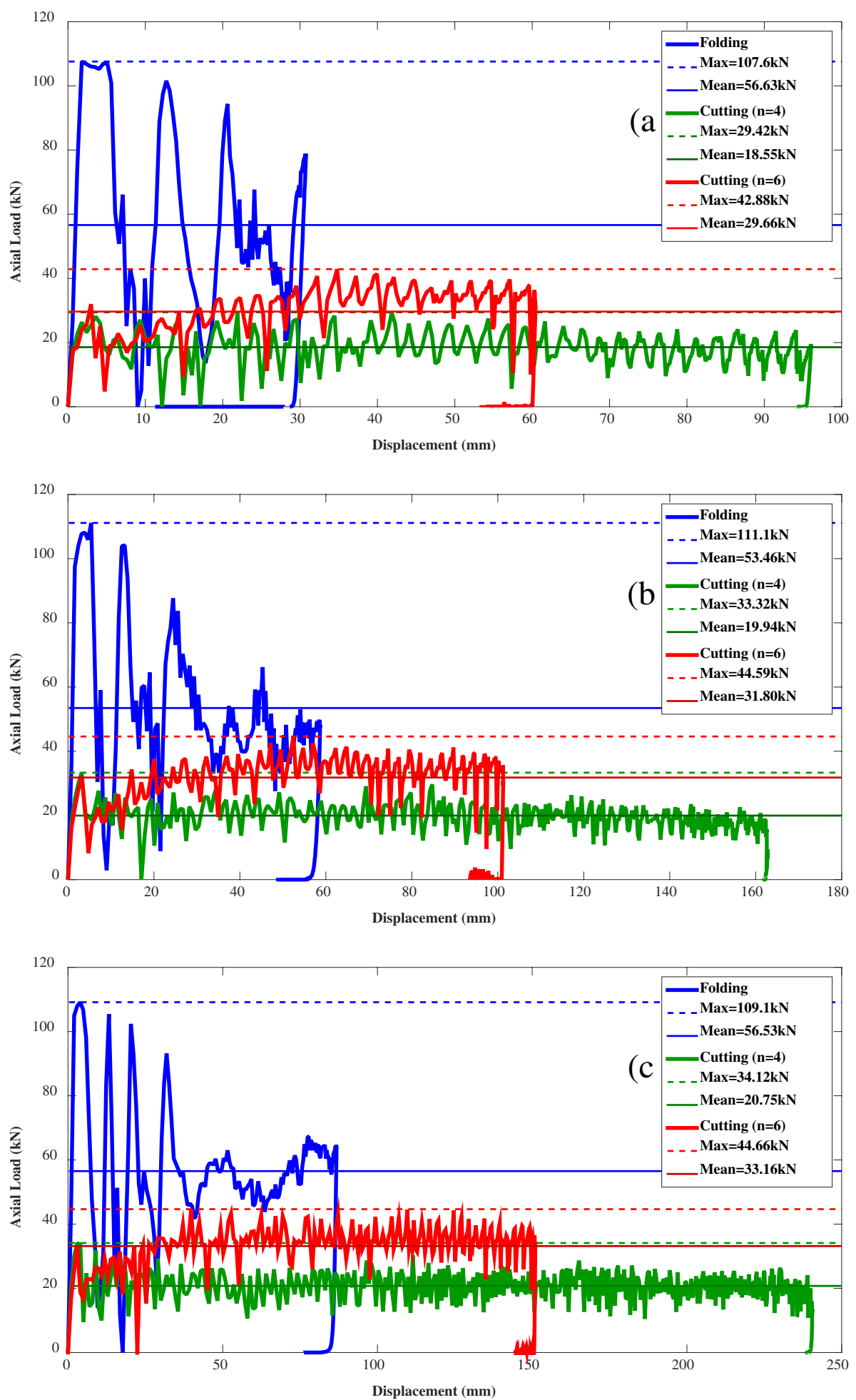

Fig. 12. Comparison of axial load-displacement diagrams for three processes: tube folding between two plates and tube rupture by 4 and 6 blades cutting tools for a tube with length of $300 \mathrm{~mm}$ and thickness of $2 \mathrm{~mm}$ (a) velocity of $6 \mathrm{~m} . \mathrm{s}^{-1}$, (b) velocity of $8 \mathrm{~m} \cdot \mathrm{s}^{-1}$, (c) velocity of $10 \mathrm{~m} \cdot \mathrm{s}^{-1}$. 

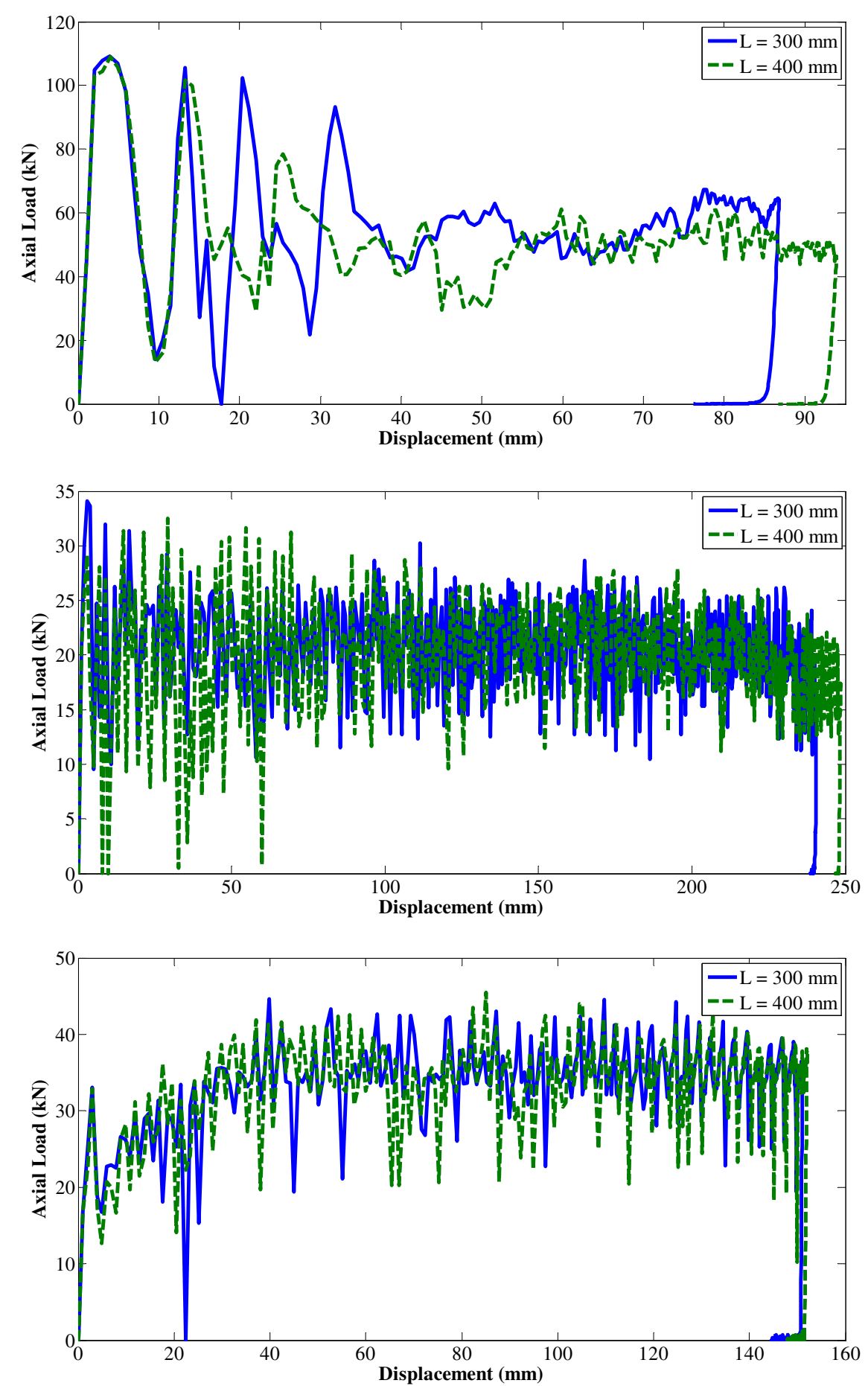

Fig. 13. Comparison of tubes with lengths of 300 and $400 \mathrm{~mm}$ and thickness of $2 \mathrm{~mm}$ for the impact with velocity of $10 \mathrm{~m} . \mathrm{s}^{-1}$ (a) tube folding between two flat plates, (b) tube rupture by the 4 blades cutting tool, (c) tube rupture by the 6 blades cutting tool.

the tube thickness is minimum ( $2 \mathrm{~mm}$ ) during tube rupture by the 4 blades cutting tool.

In Tables 1 and 2, the total energy absorption is illustrated for the three cases. Total energy absorption for three cases of folding and cutting by 4 and 6 blades are equal with the same specifications. Total energy absorption increases with the increase of impact velocity and the total energy absorption is almost constant with the increase of tube thickness. Tube's maximum total energy absorption with the length of $300 \mathrm{~mm}$ is $5.015 \mathrm{~kJ}$ for the impact velocity of $10 \mathrm{~m} \cdot \mathrm{s}^{-1}$ and tube thickness of $3 \mathrm{~mm}$ during tube rupture by the 4 blades cutting tool. Tube's maximum total energy absorption with the length of $400 \mathrm{~mm}$ is $5.107 \mathrm{~kJ}$ for the impact velocity of $10 \mathrm{~m} . \mathrm{s}^{-1}$ 
Table 1. Obtained values for three cases of tube folding between two flat plates and tube rupture by 4 and 6 blades cutting tools for the $300 \mathrm{~mm}$ length tube.

\begin{tabular}{|c|c|c|c|c|c|c|c|c|c|c|}
\hline $\begin{array}{c}\text { Impact } \\
\text { type }\end{array}$ & $\begin{array}{c}L \\
(\mathrm{~mm})\end{array}$ & $\begin{array}{c}V \\
\left(\mathrm{~m} \cdot \mathrm{s}^{-1}\right) \\
\end{array}$ & $\begin{array}{c}t \\
(\mathrm{~mm}) \\
\end{array}$ & $\begin{array}{c}\text { Max } \\
\text { Dis. }(\mathrm{mm})\end{array}$ & $\begin{array}{c}\text { Max } \\
\text { Force }(\mathrm{kN})\end{array}$ & $\begin{array}{c}\text { Mean } \\
\text { Force }(\mathrm{kN})\end{array}$ & $\begin{array}{c}\text { TEA } \\
(\mathrm{kj})\end{array}$ & $\begin{array}{c}\text { SEA } \\
\left(\mathrm{kj}^{\left.-\mathrm{kg}^{-1}\right)}\right. \\
\end{array}$ & $\begin{array}{c}\mathrm{CFE} \\
(\%)\end{array}$ & $\begin{array}{c}\text { Total } \\
\text { Time }(\mathrm{s})\end{array}$ \\
\hline Folding & 300 & 6 & 2.0 & 30.76 & 107.6 & 56.63 & 1.742 & 6.845 & 52.63 & 0.0132 \\
\hline Cutting $n=4$ & 300 & 6 & 2.0 & 96.05 & 29.42 & 18.55 & 1.782 & 7.002 & 63.06 & 0.0366 \\
\hline Cutting $n=6$ & 300 & 6 & 2.0 & 60.43 & 42.88 & 29.66 & 1.792 & 7.043 & 69.17 & 0.0210 \\
\hline Folding & 300 & 6 & 2.5 & 21.93 & 141.1 & 77.98 & 1.710 & 5.376 & 55.26 & 0.0101 \\
\hline Cutting $n=4$ & 300 & 6 & 2.5 & 76.82 & 43.52 & 23.21 & 1.783 & 5.605 & 53.33 & 0.0302 \\
\hline Cutting $n=6$ & 300 & 6 & 2.5 & 49.90 & 52.34 & 35.73 & 1.783 & 5.606 & 68.27 & 0.0175 \\
\hline Folding & 300 & 6 & 3.0 & 15.45 & 172.0 & 113.4 & 1.753 & 4.593 & 65.96 & 0.0096 \\
\hline Cutting $n=4$ & 300 & 6 & 3.0 & 62.68 & 51.02 & 29.15 & 1.827 & 4.787 & 57.14 & 0.0249 \\
\hline Cutting $n=6$ & 300 & 6 & 3.0 & 42.89 & 61.38 & 40.81 & 1.750 & 4.586 & 66.49 & 0.0149 \\
\hline Folding & 300 & 8 & 2.0 & 58.65 & 111.1 & 53.46 & 3.135 & 12.32 & 48.11 & 0.0207 \\
\hline Cutting $n=4$ & 300 & 8 & 2.0 & 162.7 & 33.32 & 19.94 & 3.246 & 12.76 & 59.86 & 0.0479 \\
\hline Cutting $n=6$ & 300 & 8 & 2.0 & 101.3 & 44.59 & 31.80 & 3.220 & 12.65 & 71.32 & 0.0264 \\
\hline Folding & 300 & 8 & 2.5 & 39.49 & 144.0 & 79.41 & 3.135 & 9.857 & 55.16 & 0.0134 \\
\hline Cutting $n=4$ & 300 & 8 & 2.5 & 132.5 & 44.52 & 24.65 & 3.267 & 10.27 & 55.37 & 0.0388 \\
\hline Cutting $n=6$ & 300 & 8 & 2.5 & 80.27 & 54.93 & 39.08 & 3.137 & 9.861 & 71.14 & 0.0209 \\
\hline Folding & 300 & 8 & 3.0 & 30.18 & 172.6 & 102.9 & 3.104 & 8.133 & 59.60 & 0.010 \\
\hline Cutting $n=4$ & 300 & 8 & 3.0 & 108.4 & 52.46 & 29.85 & 3.235 & 8.476 & 56.90 & 0.0305 \\
\hline Cutting $n=6$ & 300 & 8 & 3.0 & 68.59 & 62.34 & 47.05 & 3.227 & 8.455 & 75.48 & 0.0179 \\
\hline Folding & 300 & 10 & 2.0 & 86.77 & 109.1 & 56.53 & 4.905 & 19.27 & 51.79 & 0.0258 \\
\hline Cutting $n=4$ & 300 & 10 & 2.0 & 240.5 & 34.12 & 20.75 & 4.990 & 19.61 & 60.81 & 0.0557 \\
\hline Cutting $n=6$ & 300 & 10 & 2.0 & 151.0 & 44.66 & 33.16 & 5.007 & 19.68 & 74.25 & 0.0315 \\
\hline Folding & 300 & 10 & 2.5 & 63.29 & 144.7 & 78.17 & 4.947 & 15.55 & 54.03 & 0.0159 \\
\hline Cutting $n=4$ & 300 & 10 & 2.5 & 197.3 & 38.95 & 25.02 & 4.937 & 15.52 & 64.24 & 0.0433 \\
\hline Cutting $n=6$ & 300 & 10 & 2.5 & 120.4 & 58.15 & 41.51 & 4.998 & 15.71 & 71.39 & 0.0251 \\
\hline Folding & 300 & 10 & 3.0 & 48.39 & 177.5 & 100.4 & 4.858 & 12.73 & 56.56 & 0.0116 \\
\hline Cutting $n=4$ & 300 & 10 & 3.0 & 164.4 & 53.17 & 30.50 & 5.015 & 13.14 & 57.36 & 0.0363 \\
\hline Cutting $n=6$ & 300 & 10 & 3.0 & 102.4 & 67.06 & 47.88 & 4.903 & 12.85 & 71.40 & 0.0218 \\
\hline
\end{tabular}

and tube thickness of $3 \mathrm{~mm}$ during tube rupture by the 6 blades cutting tool. Tube's minimum total energy absorption with the length of $300 \mathrm{~mm}$ is $1.710 \mathrm{~kJ}$ for the impact velocity of $6 \mathrm{~m} . \mathrm{s}^{-1}$ and tube thickness of $2.5 \mathrm{~mm}$ during tube folding between two rigid plates. Tube's minimum total energy absorption with the length of $400 \mathrm{~mm}$ is $1.644 \mathrm{~kJ}$ for the impact velocity of $6 \mathrm{~m} . \mathrm{s}^{-1}$ and tube thickness of $3 \mathrm{~mm}$ during tube folding between two rigid plates.

Tables 1 and 2 exhibit the specific energy absorption for the three cases. The specific energy absorption is almost equal for three cases of folding and rupture by 4 and 6 blades cutting tools with the same specifications. The specific energy absorption increases with the increase of impact velocity and decreases with the increase of tube thickness. The specific energy absorption is an important parameter in design of thin-walled energy absorbers. This parameter becomes more important when vehicle designers try to decrease structure weight while increase energy absorption. With the increase of tube length from 300 to $400 \mathrm{~mm}$, the specific energy absorption reduces for all cases. The maximum specific energy absorptions for lengths of 300 and $400 \mathrm{~mm}$ are 19.68 and $14.69{\mathrm{~kJ} . \mathrm{kg}^{-1}}^{-1}$ during the rupture by the 6 blades cutting tool with the maximum velocity $\left(10 \mathrm{~m} . \mathrm{s}^{-1}\right)$ and minimum tube thickness $(2 \mathrm{~mm})$. The minimum specific energy absorption of

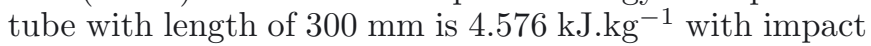

velocity of $6 \mathrm{~m} . \mathrm{s}^{-1}$ and thickness of $3 \mathrm{~mm}$ during tube rupture by the 6 blades cutting tool. The minimum specific energy absorption of tube with length of $400 \mathrm{~mm}$ is $3.230 \mathrm{~kJ} . \mathrm{kg}^{-1}$ with impact velocity of $6 \mathrm{~m} . \mathrm{s}^{-1}$ and thickness of $3 \mathrm{~mm}$ during tube folding between two blades.

Figure 14 demonstrates bar diagrams of crush force efficiency for three cases of tube folding between two plates and tube rupture by 4 and 6 blades cutting tools when impacts with velocities of 6,8 and $10 \mathrm{~m} . \mathrm{s}^{-1}$ are applied to the tubes with thicknesses of 2, 2.5 and $3 \mathrm{~mm}$ and lengths of 300 and $400 \mathrm{~mm}$. Crush force efficiency is another important parameter in designing thin-walled energy absorbers. As it is seen, the variations of crush force efficiency have not a determined trend in different conditions. Mean of crush force efficiency of tube rupture by the 6 blades cutting tool is higher than the other two ones for all situations. Next is the tube rupture by the 4 blades cutting tool and the last is the tube folding between two flat plates.

The maximum crush force efficiency of tube with length of $300 \mathrm{~mm}$ is $75.48 \%$ for the impact velocity of $8 \mathrm{~m} . \mathrm{s}^{-1}$ and tube thickness of $3 \mathrm{~mm}$ during tube rupture by the 6 blades cutting tool. The maximum crush force efficiency of tube with length of $400 \mathrm{~mm}$ is $80.19 \%$ for the impact velocity of $6 \mathrm{~m} . \mathrm{s}^{-1}$ and tube thickness of $3 \mathrm{~mm}$ during tube folding between two flat plates. The minimum crush force efficiency of tube with length of $300 \mathrm{~mm}$ 
Table 2. Obtained values for three cases of tube folding between two flat plates and tube rupture by 4 and 6 blades cutting tools for the $400 \mathrm{~mm}$ length tube.

\begin{tabular}{|c|c|c|c|c|c|c|c|c|c|c|}
\hline $\begin{array}{c}\text { Impact } \\
\text { type }\end{array}$ & $\begin{array}{c}L \\
(\mathrm{~mm})\end{array}$ & $\begin{array}{c}V \\
\left(\mathrm{~m} \cdot \mathrm{s}^{-1}\right)\end{array}$ & $\begin{array}{c}t \\
(\mathrm{~mm})\end{array}$ & $\begin{array}{c}\text { Max } \\
\text { Dis. }(\mathrm{mm})\end{array}$ & $\begin{array}{c}\text { Max } \\
\text { Force }(\mathrm{kN})\end{array}$ & $\begin{array}{c}\text { Mean } \\
\text { Force }(\mathrm{kN})\end{array}$ & $\begin{array}{c}\text { TEA } \\
(\mathrm{kj})\end{array}$ & $\begin{array}{c}\text { SEA } \\
\left(\mathrm{kj} \mathrm{kg}^{-1}\right)\end{array}$ & $\begin{array}{l}\text { CFE } \\
(\%)\end{array}$ & $\begin{array}{c}\text { Total } \\
\text { time }(\mathrm{s})\end{array}$ \\
\hline Folding & 400 & 6 & 2.0 & 27.91 & 109.9 & 62.49 & 1.744 & 5.140 & 56.85 & 0.0122 \\
\hline Cutting $n=4$ & 400 & 6 & 2.0 & 102.1 & 29.55 & 17.37 & 1.774 & 5.228 & 58.77 & 0.0390 \\
\hline Cutting $n=6$ & 400 & 6 & 2.0 & 61.32 & 41.10 & 28.93 & 1.774 & 5.229 & 70.40 & 0.0214 \\
\hline Folding & 400 & 6 & 2.5 & 19.21 & 138.7 & 91.82 & 1.764 & 4.160 & 66.22 & 0.0095 \\
\hline Cutting $n=4$ & 400 & 6 & 2.5 & 79.69 & 45.14 & 22.73 & 1.811 & 4.270 & 50.35 & 0.0311 \\
\hline Cutting $n=6$ & 400 & 6 & 2.5 & 50.14 & 51.98 & 35.43 & 1.777 & 4.189 & 68.16 & 0.0175 \\
\hline Folding & 400 & 6 & 3.0 & 12.01 & 170.7 & 136.9 & 1.644 & 3.230 & 80.19 & 0.0057 \\
\hline Cutting $n=4$ & 400 & 6 & 3.0 & 66.66 & 45.86 & 27.61 & 1.840 & 3.616 & 60.20 & 0.0247 \\
\hline Cutting $n=6$ & 400 & 6 & 3.0 & 43.16 & 62.22 & 41.12 & 1.775 & 3.487 & 66.09 & 0.0152 \\
\hline Folding & 400 & 8 & 2.0 & 59.42 & 108.0 & 53.57 & 3.183 & 9.383 & 49.59 & 0.0201 \\
\hline Cutting $n=4$ & 400 & 8 & 2.0 & 167.3 & 32.97 & 19.53 & 3.268 & 9.633 & 59.25 & 0.0465 \\
\hline Cutting $n=6$ & 400 & 8 & 2.0 & 101.1 & 43.57 & 31.39 & 3.175 & 9.357 & 72.04 & 0.0266 \\
\hline Folding & 400 & 8 & 2.5 & 38.81 & 142.5 & 81.39 & 3.159 & 7.448 & 57.13 & 0.0119 \\
\hline Cutting $n=4$ & 400 & 8 & 2.5 & 136.7 & 40.74 & 23.58 & 3.225 & 7.603 & 57.88 & 0.0390 \\
\hline Cutting $n=6$ & 400 & 8 & 2.5 & 81.96 & 56.76 & 38.91 & 3.189 & 7.520 & 68.56 & 0.0214 \\
\hline Folding & 400 & 8 & 3.0 & 28.48 & 171.6 & 107.3 & 3.056 & 6.005 & 62.53 & 0.0099 \\
\hline Cutting $n=4$ & 400 & 8 & 3.0 & 114.8 & 46.77 & 27.77 & 3.188 & 6.263 & 59.38 & 0.0326 \\
\hline Cutting $n=6$ & 400 & 8 & 3.0 & 69.44 & 65.18 & 45.90 & 3.187 & 6.263 & 70.42 & 0.0181 \\
\hline Folding & 400 & 10 & 2.0 & 93.90 & 109.0 & 52.52 & 4.932 & 14.54 & 48.17 & 0.0258 \\
\hline Cutting $n=4$ & 400 & 10 & 2.0 & 248.4 & 32.49 & 19.99 & 4.964 & 14.63 & 61.51 & 0.0545 \\
\hline Cutting $n=6$ & 400 & 10 & 2.0 & 152.0 & 45.52 & 32.79 & 4.984 & 14.69 & 72.04 & 0.0316 \\
\hline Folding & 400 & 10 & 2.5 & 61.51 & 145.4 & 79.39 & 4.883 & 11.51 & 54.59 & 0.0149 \\
\hline Cutting $n=4$ & 400 & 10 & 2.5 & 201.1 & 41.20 & 24.55 & 4.937 & 11.64 & 59.58 & 0.0446 \\
\hline Cutting $n=6$ & 400 & 10 & 2.5 & 122.1 & 55.17 & 40.27 & 4.917 & 11.59 & 73.00 & 0.0255 \\
\hline Folding & 400 & 10 & 3.0 & 45.96 & 175.8 & 104.5 & 4.803 & 9.437 & 59.45 & 0.0107 \\
\hline Cutting $n=4$ & 400 & 10 & 3.0 & 171.3 & 47.74 & 28.59 & 4.897 & 9.621 & 59.89 & 0.0380 \\
\hline Cutting $n=6$ & 400 & 10 & 3.0 & 103.0 & 66.66 & 49.60 & 5.107 & 10.04 & 74.41 & 0.0217 \\
\hline
\end{tabular}

is $48.11 \%$ for the impact velocity of $8 \mathrm{~m} \cdot \mathrm{s}^{-1}$ and tube thickness of $2 \mathrm{~mm}$ during tube folding between two flat plates. The minimum crush force efficiency of tube with the length of $400 \mathrm{~mm}$ is $48.17 \%$ for the impact velocity of $10 \mathrm{~m} . \mathrm{s}^{-1}$ and tube thickness of $2 \mathrm{~mm}$ during tube folding between two flat plates.

As it is seen in Tables 1 and 2, the maximum time of crushing is less than the maximum time of cutting with 4 and 6 blades tools. The most is the process time during the impact, the most is the chance for better and complete performance of the vehicle safety systems like seat belt and airbag.

\section{Conclusion}

In this paper, damage numerical analyses (cutting deformation and folding) of a circular tube are carried out based on ductile failure criterion to accurately obtain crashworthiness simulation results. Generally, the impact velocity has direct relationship with maximum displacement, total energy absorption and specific energy absorption for different tube dimensions and various impact velocities during tube folding between two flat rigid plates and tube rupture by 4 and 6 blades cutting tools. The maximum axial load remains constant with the increase of velocity. Tube thickness has inverse relationship with the maximum displacement and the specific energy absorption and has direct relationship with the maximum and mean axial loads. Total energy absorption remains constant with the increase of tube thickness. Tube length does not have significant effect on the obtained results in this study.

When the tube rupture occurs with the help of multiblades cutting tools, the rupture path and displacement measure are predictable while they are unpredictable during tube folding between two flat plates. Behavior of diagrams of axial load in terms of displacement and time is stable, controllable and repeatable for tube rupture by the multi-blades cutting tools while it is not possible for tube folding between two flat plates.

Considering the higher maximum force and lower crush force efficiency of folding between two plates, this case is the worst choice among three described cases. For rupture case by the 4 blades cutting tool, the maximum axial load is lower than the 6 blades one and the crush force efficiency of the 6 blades cutting tool is more than the 4 blades one. However, since the maximum displacement of the 6 blades cutting tool is less and also there is not much difference between maximum axial loads of 4 and 6 blades cutting tools, the best choice is the 6 blades cutting tool.

It seems that multi objective optimization method is required considering the tube impact conditions to obtain 


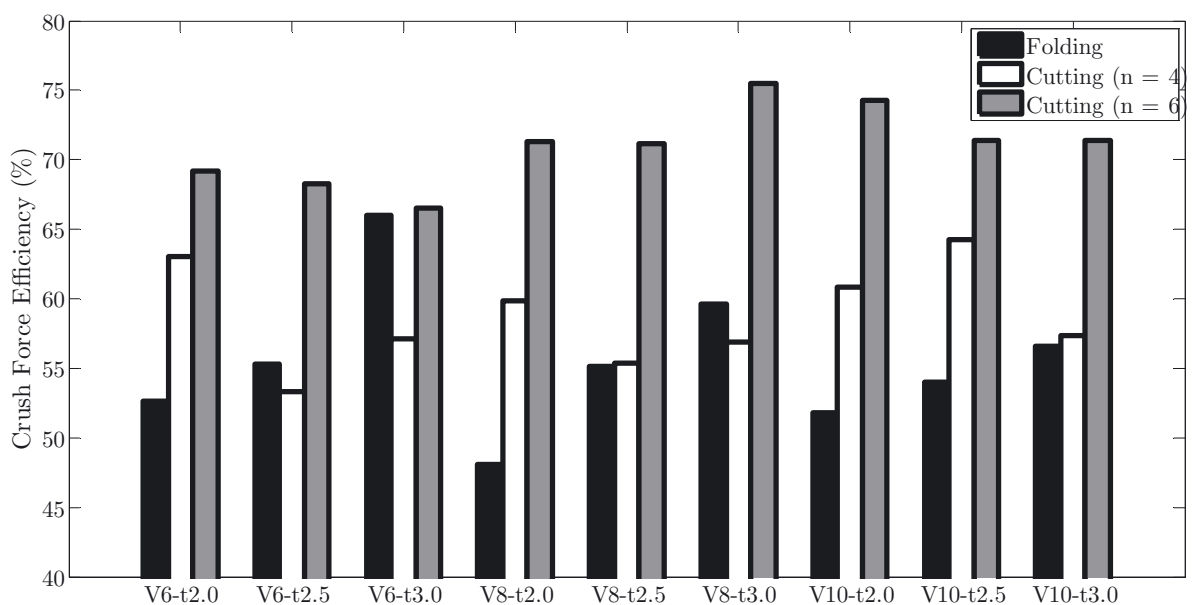

(a)

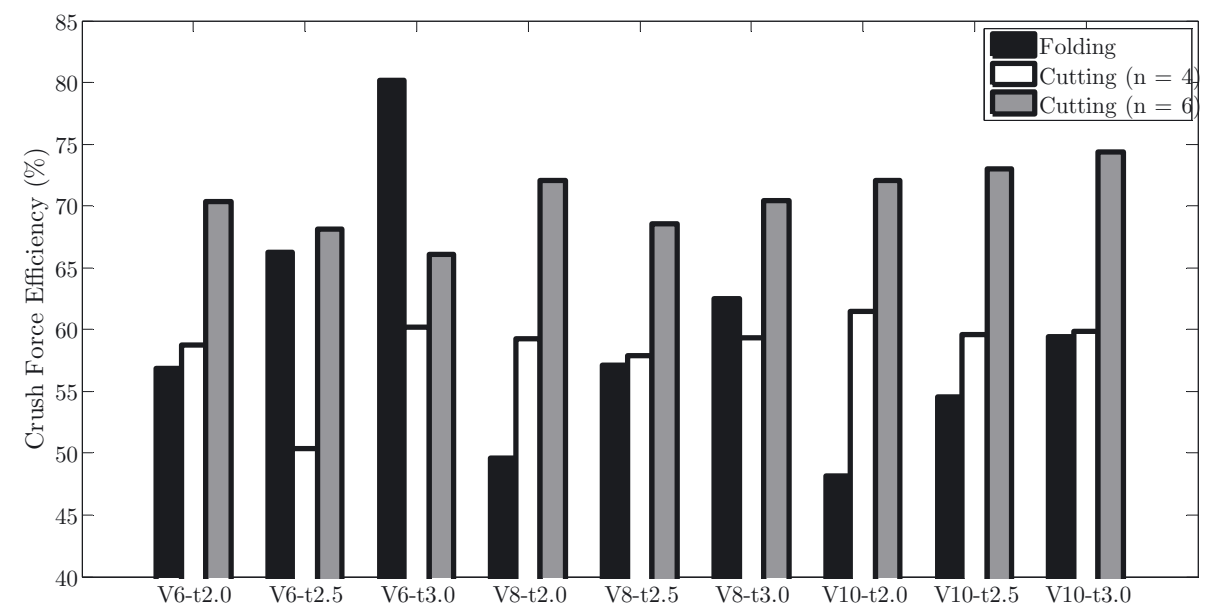

(b)

Fig. 14. Bar diagrams of crush force efficiency: (a) $L=300 \mathrm{~mm}$, (b) $L=400 \mathrm{~mm}$.

length, thickness, diameter and proper material of the tube as an energy absorber. Also, the multi objective optimization seems necessary for obtaining the number of cutting edges, the thickness of edges and the tools depth.

\section{References}

[1] Y. Zhou, F. Lan, J. Chen, Crashworthiness research on S-shaped front rails made of steel-aluminum hybrid materials, Thin-Walled Struct. 49 (2011) 291-297

[2] G. Lu, T. Yu, Energy absorption of structures and materials, Elsevier, 2003

[3] E.A. Association, Aluminum in cars, Technical report 2008, Available online at: http://www.eaa.net/upl/4/ en/doc/AluminiumincarsSept2008.pdf

[4] N.A. Alavi, J. Haddad Hamedani, Comparative analysis of energy absorption and deformations of thin walled tubes with various section geometries, ThinWalled Struct. 48 (2010) 946-954

[5] S. Reid, Plastic deformation mechanisms in axially compressed metal tubes used as impact energy absorbers, Int. J. Mech. Sci. 35 (1993) 1035-1052
[6] X.-P. Zhou, J.-H. Wang, Study on the coalescence mechanism of splitting failure of crack-weakened rock subjected to compressive loads, Mech. Res. Commun. 32 (2005) $161-171$

[7] Q. Cheng, W. Altenhof, Load/displacement and energy absorption performances of AA6061-T6 tubes under a cutting deformation mode, Int. J. Crashworthiness 10 (2005) 621-633

[8] S. Yi Jin, W. Altenhof, T. Kapoor, An experimental investigation into the cutting deformation mode of AA6061-T6 round extrusions, Thin-Walled Struct. 44 (2006) $773-786$

[9] A. Majumder, et al., Quasi-static axial cutting of AA6061 T4 and T6 round extrusions, Proc. Instit. Mech. Eng. 222 (2008) 183-195

[10] S.Y. Jin, W. Altenhof, An analytical model on the steadystate deformation of circular tubes under an axial cutting deformation mode, Int. J. Solids Struct. 48 (2011) 269279

[11] S. Chung Kim Yuen, et al., Axial splitting of circular tubes by means of blast load, Int. J. Impact Eng. 53 (2013) 17-28 
[12] A. Niknejad, B. Rezaei, G.H. Liaghat, Empty circular metal tubes in the splitting process-theoretical and experimental studies, Thin-Walled Struct. 72 (2013) 48-60

[13] J. Marzbanrad, A. Keshavarzi, F.H. Aboutalebi, Influence of elastic and plastic support on the energy absorption of the extruded aluminium tube using ductile failure criterion, Int. J. Crashworthiness 19 (2014) 172181

[14] H. Hooputra, et al., A comprehensive failure model for crashworthiness simulation of aluminium extrusions, Int. J. Crashworthiness 9 (2004) 449-464
[15] W. Kolmogorov, Spannungen deformationen bruch, 1970, p. 230

[16] M.R. Hill, T.L. Panontin, Micromechanical modeling of fracture initiation in 7050 aluminum, Eng. Fracture Mech. 69 (2002) 2163-2186

[17] J. Marzbanrad, A. Keshavarzi, A Numerical and experimental study on the crash behavior of the extruded aluminum crash box with elastic support, Latin Am. J. Solids Struct. 11 (2014) 1329-1348 